\title{
A Dose OF REALITY: UNINTENDED CONSEQUENCES OF Penalizing Hospital Readmissions in the PPACA
}

\author{
Joel D. Swider
}

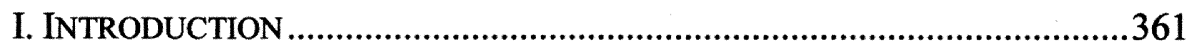

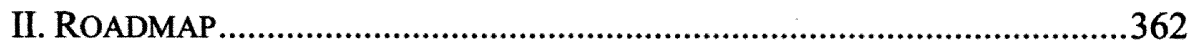

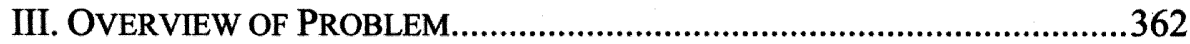

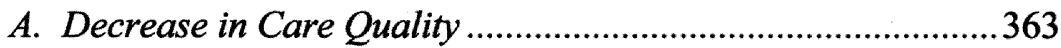

B. Decrease in Minority Access to Care .........................................363

C. Increased Hospital Financial Distress ........................................364

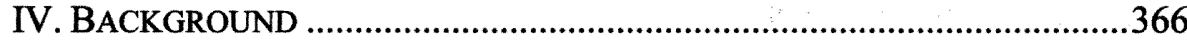

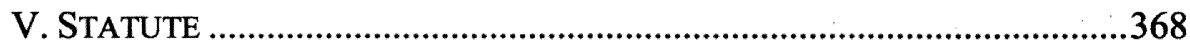

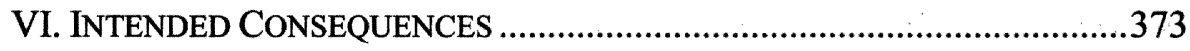

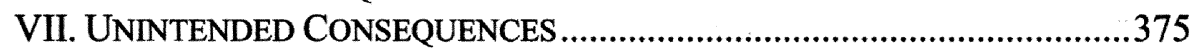

VIII. PROPOSED SOLUTIONS TO READMISSIONS-WHAT IS A

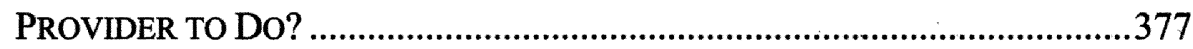

IX. POLICY IMPLICATIONS OF READMISSIONS REDUCTION ..........................381

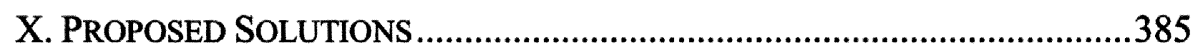

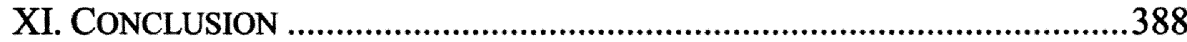

\section{INTRODUCTION}

Empirical evidence indicates that the hospital readmissions reduction provision of the Patient Protection and Affordable Care Act of $2010^{1}$ ("PPACA" or "Affordable Care Act") will likely reduce Medicare costs over the long term. ${ }^{2}$ However, this provision also will likely lead to unintended increases in hospital bankruptcies, decreases in quality of care, and decreases in access to care for minority populations.

* J.D. Candidate, 2012, Indiana University Robert H. McKinney School of Law; B.A., 2008, University of Virginia. The author wishes to thank his wife Victoria for her patience and support; Bruce Jones, J.D., for his insightful tutelage and meticulous revisions; and John Clark, M.D., J.D., for sharing his wealth of knowledge and practical expertise.

1. Patient Protection and Affordable Care Act of 2010, Pub. L. No. 111-148, 124 Stat. 119 (2010).

2. Letter from Douglas W. Elmendorf, Dir., Congressional Budget Office, to Nancy Pelosi, Speaker, U.S. House of Representatives, providing a final cost estimate of the direct spending and revenue effects of the Patient Protection and Affordable Care Act 26 (Mar. 20, 2010), available at $\mathrm{http}: / / \mathrm{www} . c b o . g o v / \mathrm{ftpdocs} / 113 \mathrm{xx} / \mathrm{doc} 11379 /$ AmendReconProp.pdf. 


\section{ROADMAP}

This Note will first provide a definition for what constitutes hospital "readmissions" under the Affordable Care Act. Next, it will highlight the economic harm readmissions pose to federal spending and reining in the budget deficit. Third, this Note will explain Congress' proposed solution to this problem-namely, the Hospital Readmissions Reduction Programand its intended outcome of reducing Medicare costs. The majority of this Note will then consist in analyzing the unintended consequences on hospitals and patients, both directly and indirectly, using interviews with Indiana hospital administrators and published data regarding the successful readmissions reduction efforts of various states and hospitals. ${ }^{3}$ The Note will conclude by offering possible improvements on the current state of the Hospital Readmissions Reduction Program.

\section{OVERVIEW OF PROBLEM}

The phenomenon of hospital readmissions is a prevalent and costly one. According to a 2009 study in the New England Journal of Medicine, almost one-fifth (19.6\%) of hospitalized Medicare patients are readmitted to a hospital within 30 days of their initial stay. ${ }^{4}$ In 2004, unplanned rehospitalizations cost taxpayers roughly $\$ 17.4$ billion of the total $\$ 102.6$ billion the government disbursed for Medicare. ${ }^{5}$ All told, nearly seventeen percent of the Medicare budget was spent on unplanned readmissions. ${ }^{6}$

Congress attempted to address this problem as part of the recently passed Affordable Care Act." The particular provision, the so-called "Hospital Readmissions Reduction Program"8 ("HRRP" or "Program") goes into effect October 1, 2012, and stipulates that the government will begin to reduce the amount it pays to hospitals with "excess readmissions" of patients.

The Congressional Budget Office ("CBO") predicts that this program

3. See State Health Watch, Colorado Medicaid Set to Save Millions on Readmissions, PHARMACY CHOICE (July 1, 2010), http://www.pharmacychoice.com/news/article. cfm?Article ID $=605072$.

4. Stephen F. Jencks et al., Rehospitalizations Among Patients in the Medicare Feefor-Service Program, 360 NEw ENG. J. MED. 1418, 1426 (2009).

5. Ann Carrns, Health Reform Takes Aim at Hospital Readmission Rates, US NEWS \& WORLD REPORT (July 21, 2010), http://health.usnews.com/health-news/best-hospitals/ articles $/ 2010 / 07 / 21 /$ health-reform-takes-aim-at-hospital-readmission-rates.html.

6. $17.4 \div 102.6=16.96 \%$.

7. Patient Protection and Affordable Care Act of 2010, Pub. L. No. 111-148, 124 Stat. 119 (2010).

8. Patient Protection and Affordable Care Act of 2010, Pub. L. No. 111-148, $\S 3025$, 124 Stat. 119, 408 (2010) amended by $\S 10309,124$ Stat. 119, 942 (2010) (codified as amended at 42 U.S.C. $\$ 1395 w w(q)(2010))$.

9. See generally 42 U.S.C. $\$ 1395 w w(q)(4)(C)(2010)$. 
alone will save Medicare an aggregate $\$ 7.1$ billion by fiscal year $2019 .^{10}$ However, the measure may have at least three unintended consequences: (A) a decrease in quality of care; (B) a decrease in access to care for minorities; and (C) an increase in hospital financial distress, including increased prevalence of bankruptcy.

\section{A. Decrease in Care Quality}

Cash-strapped hospitals will need to conserve as much federal money as they can, which may create a conflict of interest between quality of care delivered and hospital bottom lines. In an interview with the National Law Journal, Anna Grizzle, a partner at Bass, Berry, and Sims in Nashville, Tennessee, who represents health care providers, explained that cost-cutting will be "crucial" to the survival of publicly funded hospitals in the era of the Affordable Care Act. ${ }^{11}$ She anticipates that hospitals will be faced with more difficult dilemmas as to who should receive care and under what conditions: "[F]or example, a patient who comes in with a heart attack, is that person readmitted for care?"12 The humanitarian in us hopes so; however, under the Affordable Care Act, the hospital will be penalized for this readmission. Therefore, hospitals will "need to look for ways to ensure those patients are not readmitted." ${ }^{\prime 3}$ This may create a kind of race to the bottom in which hospitals are forced to cut back on services in order to remain viable. Indeed, a New England Journal of Medicine study published in December 2011 found, somewhat paradoxically, that there was "a substantial association" between "overall [hospital] admission rates" and "rates of rehospitalization." "14 The study indicated that "lower utilization of hospital services might be more successful in reducing readmissions" ${ }^{15}$ than other methods tried to date.

\section{B. Decrease in Minority Access to Care}

Beyond the problem of care quality lies the troubling fact that readmissions tend to be higher in hospitals that treat a greater proportion of Af-

10. Letter from Douglas W. Elmendorf, Dir., Congressional Budget Office, to Nancy Pelosi, Speaker, U.S. House of Representatives, providing a final cost estimate of the direct spending and revenue effects of the Patient Protection and Affordable Care Act 26 (Mar. 20, 2010), available at http://www.cbo.gov/ftpdocs/113xx/doc11379/AmendReconProp.pdf.

11. Amanda Bronstad, Suit over Hospital's Closure Could be a Harbinger, NAT'L L.J. (Aug. 23, 2010), http://www.law.com/jsp/nlj/PubArticleNLJ.jsp?id=1202470936728\& slreturn=1\&hbxlogin=1\#.

12. Id.

13. Id.

14. Arnold M. Epstein et al., The Relationship Between Hospital Admission Rates and Rehospitalizations, 365 NEW ENG. J. MED. 2287, 2287 (2011).

15. Id. 
rican-Americans and needy patients. ${ }^{16}$ This situation makes sense considering the direct correlation between inferior socio-economic conditions and poor population health. ${ }^{17}$ In addition, patients who are beneficiaries of both Medicare and Medicaid-a status known as dual-eligibility-are monitored on a yearly basis, rather than a simple thirty-day cycle. ${ }^{18}$ Thus, hospitals treating dual-eligible patients have an entire yearlong period during which to worry about preventing readmissions. Dual-eligible patients also tend to be sicker than the average Medicare enrollee. ${ }^{19}$ Add to this the fact that more than half of public hospital patients are racial and ethnic minorities, ${ }^{20}$ and it becomes readily apparent that the hospitals that have the most to lose are those with higher minority and poor patient populations. If a community hospital is experiencing increased pressure to cut patient services, then the entire community suffers. Thus, the Program may stand to disproportionately penalize public hospitals that are the most tasked with treating minorities and the poor.

\section{Increased Hospital Financial Distress}

Finally, in recent years, an increasing number of hospitals throughout the country have filed for bankruptcy. ${ }^{21}$ According to Anna Grizzle and

16. Karen E. Joynt et al., Thirty-Day Readmission Rates for Medicare Beneficiaries by Race and Site of Care, 305 JAMA 675, 675 (2011); Richard Cooper, Hospital Readmission Policy Flawed, ACTION FOR BETTER HEALTHCARE Blog (Aug. 13, 2010), http://actionforbetterhealthcare.com/?p=1067; see also Roxana Guilford-Blake, Medicaid Status, Race Linked with Hospital Readmissions, HEALTHLEADERS MEDIA, Oct. 15, 2010, http:/www.healthleadersmedia.com/content/LED-257766/Medicaid-Status-Race-Linkedwith-Hospital-Readmissions (finding that, after adjustments for other variables, being African-American raises risk of readmission by forty-three percent and being a Medicaid beneficiary raises risk of readmission by fifteen percent); but see Lena M. Chen et al., Hospital Cost of Care, Quality of Care, and Readmission Rates: Penny-Wise and Pound-Foolish?, 170 ARCHIVES INTERNAL MED. 340, 340 (2010) (finding limited evidence to support the "penny-wise and pound-foolish" hypothesis: that low-cost hospitals discharge patients earlier but have higher readmission rates and greater downstream inpatient costs).

17. For an analysis of the relationship between poverty and ill-health, see Adam Wagstaff, Poverty and Health Sector Inequalities, 80(2) BULL. WORLD HEALTH ORG. 97, $97-$ 100 (2002), available at http:/www.who.int/docstore/bulletin/pdf/2002/bul-2-E-2002/80\% $282 \% 2997-105$.pdf.

18. Telephone interview with John Clark, Medical Director of Clinical Informatics, Indiana University Health (Feb. 2, 2011).

19. Medicare Payment AdVisory Comm'n, Report to the Congress: Medicare AND THE HEALTH CARE DELIVERY SYSTEM 123 (2011), available at http:/www.medpac.gov/ documents/jun11_entirereport.pdf; telephone interview with John Clark, Medical Director of Clinical Informatics, Indiana University Health (Feb. 2, 2011).

20. Marsha RegensteIn \& Donna SiCKLer, Nat'l Ass'N OF PUB. Hosp. \& Health Sys., Race, Ethnicity, and Language of Patients: Hospital Practices Regarding COLLECTION OF INFORMATION TO ADDRESS DisPaRITIES IN HEALTH CARE ix (2006), available at http://www.naph.org/Main-Menu-Category/Our-Work/Health-Care-Disparities/race ethnicityandlanguageofpatients.aspx ?FT $=$.pdf.

21. Bronstad, supra note 11. 
others, this is due to mounting and unsustainable pressures on hospitals to cut costs. $^{22}$ These pressures include growing costs, decreasing revenues, and unsustainable debt loads. ${ }^{23}$ A New York City hospital executive was quoted as saying,

If you've accumulated any reserve over time, the first thing you do is eat it up. Then you cut costs on staffing and support services, sometimes below levels you know are safe. Then you stop spending money to keep your physical plant and equipment up to date. . . . Then, when there's nothing else you can do, you declare bankruptcy. ${ }^{24}$

The danger then becomes that "[r]emaining hospitals, struggling to cope with the costs imposed by an influx of new, mostly poor patients left behind by the places that shut down, will increasingly be overcrowded and understaffed. Services will be curtailed. Facilities will be degraded. Long waits and uneven care could become the norm." 25 Grizzle likewise predicts that pressures such as these are set to intensify with the implementation of the HRRP. ${ }^{26}$

Although lawmakers may have been unaware of these unintended consequences at the time the Affordable Care Act was passed, ${ }^{27}$ many of these same criticisms were brought before the Centers for Medicare and Medicaid Services ("CMS") during the notice-and-comment period ${ }^{28}$ prior to publishing its final rule ${ }^{29}$ regarding the HRRP. Since CMS changed almost nothing about the Program between issuing the proposed rule and the

22. Id.

23. Mark Levine, St. Vincent's is the Lehman Brothers of Hospitals, N.Y. MAG., Oct. 17, 2010, available at $\mathrm{http}: / /$ nymag.com/news/features/68991/.

24. Id.

25. Id.

26. Bronstad, supra note 11.

27. See, e.g., Jordan Fabian, Key Senate Democrat Suggests that He Didn't Read Entire Healthcare Reform Bill, THE HILl's BLOG BRIEFING ROOM (Aug. 25, 2010, 09:40 AM), http://thehill.com/blogs/blog-briefing-room/news/115749-sen-baucus-suggests-he-did-notread-entire-health-bill; David Freddoso, Pelosi on Health Care: 'We Have to Pass the Bill so You Can Find out What Is in It . . .', WASH. EXAM'R (Mar. 9, 2010, 4:00 AM), http://washingtonexaminer.com/blogs/beltway-confidential/pelosi-health-care-039we-havepass-bill-so-you-can-find-out-what-it039.

28. See Medicare Program; Proposed Changes to the Hospital Inpatient Prospective Payment Systems for Acute Care Hospitals and the Long-Term Care Hospital Prospective Payment System and Fiscal Year 2012 Rates, 76 Fed. Reg. 25,788 (proposed May 5, 2011) (to be codified at 42 C.F.R. pts. 412, 413, 476).

29. Medicare Program; Hospital Inpatient Prospective Payment Systems for Acute Care Hospitals and the Long-Term Care Hospital Prospective Payment System and FY 2012 Rates; Hospitals' FTE Resident Caps for Graduate Medical Education Payment, 76 Fed. Reg. 51,476 (Aug. 18, 2011) [hereinafter CMS Final Rule] (to be codified at 42 C.F.R. pts. $412,413,476)$. 
final rule, lawmakers should amend the Affordable Care Act to address these issues in light of new research and other critical analyses.

\section{BACKGROUND}

The concept of hospital readmission (also called rehospitalization) is relatively simple and also relatively broad - a patient, upon discharge from a hospital, is soon thereafter readmitted to the same or a different hospital for the same or a different condition. ${ }^{30}$ The main problem with readmitting patients is that this "sometimes indicate[s] poor care or missed opportunities to better coordinate care," and is related to the patient's original condition. Research has indicated that excessive readmissions can be avoided through better communication between caregivers and patients and better coordination of care following discharge. ${ }^{32}$

In its June 2007 report to Congress, the Medicare Payment Advisory Commission ("MedPAC") noted that Medicare has not previously rewarded hospitals' efforts to reduce readmissions. ${ }^{33}$ To the contrary, Medicare "pays for all admissions based on the patient's diagnosis regardless of whether it is an initial stay or a readmission for the same or a related condition. ${ }^{, 34}$ As a result, there is no incentive for hospitals to cut down on readmission rates. In fact, with its system of "case-based payments that reward hospitals for shorter lengths of stay," ${ }^{35}$ hospitals are perhaps even "more likely to discharge patients earlier," regardless of any increased risk of readmission. ${ }^{36}$

This is a prevalent problem. In 2005, $6.2 \%$ of hospitalizations among Medicare beneficiaries resulted in readmission within seven days, and $17.6 \%$ of hospitalizations resulted in readmission within thirty days. ${ }^{37} \mathrm{~A}$ study in the New England Journal of Medicine pegged the rate of Medicare beneficiaries requiring readmission within thirty days of initial discharge even higher, at $19.6 \%$, or almost one-fifth of patients. ${ }^{38}$ Furthermore, $67.1 \%$ of patients discharged following a hospitalization related to a medical condition and $51.5 \%$ of those discharged after surgical procedures were

30. Hospital Readmissions Measures, U.S. DeP'T OF HeALTH \& HUMAN SERVS., http://www.hospitalcompare.hhs.gov/staticpages/for-consumers/ooc/readmissionmeasures.aspx (last visited Jan. 27, 2012).

31. Medicare Payment AdVisory Comm'N, Report to the Congress: Promoting GREATER EFFICIENCY IN MEDICARE 105 (2007), available at http://www.medpac.gov /documents/Jun07_EntireReport.pdf.

32. Id.

33. Id.

34. Id.

35. Id.

36. Id. at $105-6$.

37. Id. at 107.

38. Stephen F. Jencks et al., Rehospitalizations Among Patients in the Medicare Feefor-Service Program, 360 NEw ENG. J. MED. 1418, 1420 (2009). 
rehospitalized or died within a year. ${ }^{39}$

This is also a very costly problem. In 2005, the average Medicare payment for a "potentially preventable readmission" was $\$ 7,200$. $^{40} \mathrm{Re}$ searchers have estimated that the aggregate Medicare cost of unplanned rehospitalizations in 2004 was $\$ 17.4$ billion. $^{41}$

Nonetheless, as evidenced by hospitals with comparatively lower rates of readmission, this problem is potentially a solvable one. For example, 2005 data shows that the fifteen-day readmission rate ranges from six percent for hospitals in the top tenth percentile to double that, or twelve percent, for hospitals in the ninetieth percentile. ${ }^{42}$ It should also be noted that readmission rates are affected in large part by the mix of cases a particular hospital sees. ${ }^{43}$

In light of this problem and its lack of a clear market-based solution, MedPAC provided the framework for a two-step policy meant to address the problem of excessive readmissions through financial incentives that reward hospitals for reducing their readmission numbers. ${ }^{44}$ The first prong of the suggested strategy is to collect and publicize data regarding hospitalspecific readmission rates for certain medical conditions. ${ }^{45}$ "This will ensure that hospitals know their rates and how they compare with those of their peers and will allow beneficiaries and other providers to use this information when they make health care decisions or admit patients." the second prong, MedPAC recommends that, "[a]fter a year or two, public disclosure could be complemented by a change in payment rates, so that hospitals with high risk-adjusted rates of readmission receive lower average per case payments. ${ }^{, 47}$ MedPAC declined to give any guidance as to how or at what rate these lower average case payments were to be meted out. ${ }^{48}$ MedPAC also pointed out that holding each provider along the continuum ${ }^{49}$ accountable would be an "important parallel policy" to encourage decreasing readmissions, since ultimate success in reducing readmission rates and attendant costs depends upon efficiency and coordination among all members of the provider chain. ${ }^{50}$ Finally, MedPAC advocated payment incen-

39. Id. at 1421.

40. MEDiCARE PAYMENT AdVISORY COMm'N, supra note 31, at 108.

41. Jencks et al., supra note 38, at 1426.

42. MEDICARE PAYMENT ADVISORY COMM'N, supra note 31, at 108-9.

43. Id. at 109 .

44. Id. at $103,114$.

45. Id. at 114 .

46. Id.

47. Id.

48. Id. at 261 .

49. The "continuum" of care encompasses the comprehensive array of health service professionals who see a given patient for treatment. This includes physicians, skilled nursing facilities, home health providers, and other providers. See MEDICARE PAYMENT ADVISORY COMM'N, supra note 31, at 114.

50. MEdiCARE PAYMENT AdVISORY COMM'N, supra note 31, at 114. 
tives to reward quality care. ${ }^{51}$

Prior to passage of the Affordable Care Act, CMS began implementing the first prong of the MedPAC strategy. Beginning in 2002, in association with the Hospital Quality Alliance, CMS began collecting data from hospitals on a voluntary basis for the purpose of making "important information about hospital performance accessible to the public and to inform and invigorate efforts to improve quality."52 With passage of the Affordable Care Act, CMS began requiring hospitals that treat Medicare patients to submit readmissions data, ${ }^{53}$ specifically regarding three conditions: acute myocardial infarction (heart attack), congestive heart failure, and pneumonia. ${ }^{54}$ This data is available on the CMS "Hospital Compare" Internet website. ${ }^{55}$ The website also includes a comparison of each hospital's statistics to national averages. While patients and potential patients have undoubtedly benefited through greater transparency and a larger volume of data to compare in making hospital decisions, the program lacked any real mechanism to encourage hospitals to reduce readmissions until passage of the Affordable Care Act.

\section{STATUTE}

Heeding MedPAC's advice, ${ }^{56}$ in 2010 , Congress attempted to address some of the problems with the state of hospital readmissions through passage of the Affordable Care Act. ${ }^{57}$ In particular, section $3025,{ }^{58}$ as amended by section $10309^{59}$ - the "Hospital Readmissions Reduction Program"60 provides as follows:

(1) In General. [B]eginning on or after October 1, 2012 , in order to account for excess readmissions in

51. Id. at $77,114$.

52. Medicare Hospital Compare Glossary, U.S. DeP'T OF HEALTH AND HUMAN SERVS., http://www.hospitalcompare.hhs.gov/staticpages/help/hospital-glossary.aspx?Choice $=\mathrm{H}$ (last visited Jan. 21, 2012).

53. 42 U.S.C. $\S 1395 w w(q)(8)(B)(2010)$.

54. See Changes to the Hospital Inpatient Prospective Payment Systems and Fiscal Year 2009 Rates, 73 Fed. Reg. 48,434, 48,602 (Aug. 19, 2008).

55. Hospital Compare, U.S. DeP'T OF Health AND HuMan SERVS., http://www. hospitalcompare.hhs.gov/ (last updated Jan. 26, 2012).

56. CMS Final Rule, 76 Fed. Reg. 51,476, 51,778 (Aug. 18, 2011) (to be codified at 42 C.F.R. pts. 412, 413, 476); see generally MEDICARE PAYMENT ADVISORY COMM’N, supra note 31 .

57. Patient Protection and Affordable Care Act of 2010, Pub. L. No. 111-148, 124 Stat. 119 (2010).

58. Patient Protection and Affordable Care Act of 2010, Pub. L. No. 111-148, § 3025, 124 Stat. 119 (2010) (codified as amended at 42 U.S.C. $\$ 1395 w w(q)(2010)$ ).

59. Patient Protection and Affordable Care Act of 2010, Pub. L. No. 111-148, § 10309,124 Stat. 119 (2010) (codified as amended at 42 U.S.C. $§ 1395 w w(q)(2010)$ ).

60. 42 U.S.C. $\S 1395 w w(q)(2010)$. 
the hospital, the Secretary shall make payments . . . in an amount equal to the product of --

(A) the base operating DRG payment amount . . . for the discharge; and

(B) the adjustment factor . . . for the hospital for the fiscal year.

(2) Base operating DRG ["diagnosis related group"] payment amount defined.

(A) In general. [T] he term "base operating DRG payment amount" means, with respect to a hospital for a fiscal year--

(i) the payment amount that would otherwise be made ... for discharge if this subsection did not apply

(3) Adjustment factor.

(B) Ratio. The ratio described in this subparagraph for a hospital for an applicable period is equal to 1 minus the ratio of-sions .... and

(i) the aggregate payments for excess readmis-

(ii) the aggregate payments for all discharges . .

(4) Aggregate payments, excess readmission ratio defined. For purposes of this subsection:

(A) [T] he term "aggregate payments for excess readmissions" means, for a hospital for an applicable period, the sum, for applicable conditions ... . of the product, for each applicable condition, of--

(i) the base operating DRG payment amount for such hospital for such applicable period for such condition;

(ii) the number of admissions for such condition for such hospital for such applicable period; and

(iii) the excess readmissions ratio .... for such hospital for such applicable period minus 1 .

(B) $[\mathrm{T}]$ he term "aggregate payments for all discharges" means, for a hospital for an applicable period, the sum of the base operating DRG payment amounts for all discharges for all conditions from such hospital for such applicable period.

(C) Excess readmission ratio.

(i) $[\mathrm{T}]$ he term "excess readmissions ratio" means, with respect to an applicable condition for a hospital for an applicable 
period, the ratio (but not less than 1.0) of--

(I) the risk adjusted readmissions

based on actual readmissions ... . for an applicable hospital for such condition with respect to such applicable period; to

(II) the risk adjusted expected readmissions . . . for such hospital for such condition with respect to such applicable period. ${ }^{61}$

In other words, starting in fiscal year 2013, the typical, prospective diagnosis related group ("DRG") payment that Medicare makes to a hospital will be reduced based on the number of readmissions at that hospital above the national average readmission rate $^{62}$ for a particular condition. This payment reduction will apply to all Medicare discharges for that condition, even those that did not result in a readmission. ${ }^{63}$ Thus, once the threshold is met, the hospital is penalized whether or not it later curtails readmissions for the rest of that year.

Presently, DRG payments are issued prospectively based on the physician's documentation of a patient's diagnosis. ${ }^{64}$ The U.S. Department of Health and Human Services ("HHS") also takes into account such things as prevailing wage rates in the hospital's geographic region. ${ }^{65}$ But these base amounts are always multiplied by the DRG "weight" as an adjustment factor, which varies depending on the national average standardized cost per case for a specific type of diagnosis. ${ }^{66}$ The weights are generalized based on diagnosis because they are intended to account for cost variations between different treatments for the same condition; some patients may require more costly care (for example, a longer-than-average hospital stay) while some patients may respond extremely well to less expensive treat-

61. Id.

62. There is actually nothing in the statute that mentions national averages per se, but DRG payments are currently calculated based on such a scheme, and MedPAC's June 2007 Report to the Congress, from which many of the ideas for the PPACA's readmissions reduction provision came, calculated expected rates as based on "the average rate of readmission across all hospitals, controlling for all patient refined diagnosis related group and severity class of patients." Presumably, the term "risk adjusted expected readmissions" takes into account a national average. See MediCARE PAYMENT ADVISORY COMM'N, supra note 31, at $111-12$.

63. See 42 U.S.C. $\S 1395 \mathrm{ww}(\mathrm{q})(4)(A)$ (2010) for the precise calculation.

64. Social Security Act $\S 1886$ (d), 42 U.S.C. $\S 1395$ ww(d) (2010); PAUL GOTTLOBER et al., U.S. Dep't of Health \& Human Servis., Medicare Hospital Prospective PAYMENT SYSTEM: How DRG RATES ARE CALCULATED AND UPDATED 1, 5 (2001), available at http://oig.hhs.gov/oei/reports/oei-09-00-00200.pdf.

65. Paul Gottlober et al., U.S. Dep't of Health and Human Servis., Medicare Hospital Prospective Payment System: How DRG Rates are Calculated and UPDATED 6-7 (2001), available at http://oig.hhs.gov/oei/reports/oei-09-00-00200.pdf.

66. Id. at 8 . 
ment. ${ }^{67}$ In the end, these payments should average out to properly reimburse the hospital for its costs of care.

Thus, the "excess readmissions ratio" limits the base operating DRG payments in an amount equal to the ratio of actual readmissions to "expected readmissions." pected readmissions should be calculated, but the CMS final rule states that expected readmissions are the sum of "the probability of readmission for each patient at an average hospital." calculated using "[t]he intercept term for the model (the same for all hospitals ... )" and "[t]he increase or decrease in the probability of readmission contributed by each of the patient's risk factors (risk adjustment coefficients multiplied by the patient's risk factors ... .)."70 The statute defines a "readmission" as, "in the case of an individual who is discharged from an applicable hospital, the admission of the individual to the same or another applicable hospital within a time period specified by the Secretary from the date of such discharge." 71 The final rule provided that "The time period specified . . is 30 days." 72

Within the three categories of so-called "endorsed measures," gress carved out "exclusions for readmissions that are unrelated to the prior discharge (such as a planned readmission or transfer to another applicable hospital)."74 However, in 2015, the HHS Secretary shall, to the extent practicable, expand the applicable conditions beyond the 3 conditions for which measures have been endorsed . . . to the additional 4 conditions that have been identified by the Medicare Payment Advisory Commission in its report to Congress in June 2007 and to other conditions and procedures as determined appropriate by the Secretary. ${ }^{75}$

These other "appropriate" conditions will be updated by the Secretary of Health and Human Services through regulations, ${ }^{76}$ but CMS indicated that it initially still "plan[s] to consider the remaining four conditions",77 contemplated by MedPAC. ${ }^{78}$ These conditions include chronic obstructive

67. See generally id.

68. 42 U.S.C. $\S 1395 \mathrm{ww}(\mathrm{q})(4)(\mathrm{C})(\mathrm{i})(2010)$.

69. CMS Final Rule, 76 Fed. Reg. $51,476,51,675$ (Aug. 18, 2011) (to be codified at 42 C.F.R. pts. $412,413,476)$.

70. $I d$.

71. 42 U.S.C. $\S 1395 w w(q)(5)(E)$ (2010) (emphasis added).

72. CMS Final Rule, 76 Fed. Reg. 51,476, 51,666 (Aug. 18, 2011) (to be codified at 42 C.F.R. pts. $412,413,476$ ).

73. 42 U.S.C. $\S 1395 \mathrm{ww}(\mathrm{q})(5)(\mathrm{A})(\mathrm{ii})(\mathrm{II})(2010)$. The three endorsed measures are acute myocardial infarction, congestive heart failure, and pneumonia. U.S. DEP'T OF HEALTH \& HUMAN SERVS., supra note 55.

74. 42 U.S.C. $\$ 1395 w w(q)(5)(A)($ ii)(II) (2010).

75. 42 U.S.C. $\S 1395 \mathrm{ww}(\mathrm{q})(5)(\mathrm{B})(2010)$.

76. CMS Final Rule, 76 Fed. Reg. 51,476, 51,664 (Aug. 18, 2011) (to be codified at 42 C.F.R. pts. $412,413,476)$.

77. Id.

78. See Medicare Payment Advisory Comm'n, supra note 31. 
pulmonary disease (COPD), coronary artery bypass graft surgery (CABG), percutaneous transluminal coronary angioplasty (PTCA), and "other vascular" surgery admissions. ${ }^{79}$

There are certain limited exemptions to the readmissions payment reduction for "sole community hospitals" and for "medicare-dependent, small rural hospitals." ${ }^{80}$ Hospitals which treat "fewer than a minimum number (as determined by the Secretary) of discharges for such applicable condition for the applicable period"81 are also exempt from the payment reduction. Apparently Congress thought that the importance of maintaining access to these hospitals outweighed the risk of possible service cutbacks or financial decline as a result of the Program.

Finally, the Affordable Care Act's HRRP ${ }^{82}$ includes a "floor adjustment factor," which cannot be lower than 0.99 for fiscal year 2013, 0.98 for fiscal year 2014, or 0.97 for fiscal years 2015 and later. ${ }^{83}$ This means that the largest potential payment reduction a hospital could receive would be $1 \%$ in fiscal year 2013, 2\% in fiscal year 2014, and 3\% in fiscal years 2015 and beyond. ${ }^{84}$ This "phased-in approach" ${ }^{\text {"85 }}$ allows hospitals some time to ease into the program and make adjustments before the full penalty kicks into effect.

Other provisions within the Affordable Care Act require that, by March 2012, the HHS Secretary develop "reporting requirements" for use by health plans to "implement activities to prevent hospital readmissions through a comprehensive program for hospital discharge that includes patient-centered education and counseling, comprehensive discharge planning, and post discharge reinforcement by an appropriate health care professional." requirements should supplant, rather than augment, any requirement for total readmission rates. ${ }^{87}$ Nonetheless, Congress apparently saw both as important as it ultimately required both.

There still exist some uncertainties regarding the exact details of the HRRP. Although the CMS regulations issued in August 2011 comprise a "final rule," ${ }^{, 88}$ there are a number of decisions the HHS Secretary still must

79. Id. at 116 .

80. 42 U.S.C. $\S 1395 w w(q)(2)(B)(i)(2010)$.

81. 42 U.S.C. § $1395 \mathrm{ww}(\mathrm{q})(4)(\mathrm{C})(\mathrm{ii})(2010)$.

82. See 42 U.S.C. $\S 1395 \mathrm{ww}(\mathrm{q})(2010)$.

83. 42 U.S.C. $\$ 1395 w w(q)(3)$ (C)(i)-(iii) (2010).

84. See Sharon Burnett, Mo. Hosp. Ass'N, Hospital Readmissions Reduction ProGram 1 (2010), available at http://web.mhanet.com/UserDocs/Hospital_Readmissions_ Reduction_Program.pdf.

85. CMS Final Rule, 76 Fed. Reg. 51,476, 51,662 (Aug. 18, 2011) (to be codified at 42 C.F.R. pts. $412,413,476$ ).

86. Patient Protection and Affordable Care Act of 2010, Pub. L. No. 111-148, § 2717(a)(1)(B), 124 Stat. 119, 135 (2010).

87. See infra Part X.

88. CMS Final Rule, 76 Fed. Reg. 51,476, 51,664 (Aug. 18, 2011) (to be codified at 
make in order to flesh out the program entirely. Most momentous among these include: precise calculations of the base operating DRG payment amount, including policies for sole community hospitals and Medicaredependent, small rural hospitals; both the ratio and floor adjustment factors; calculations of aggregate payments for excess readmissions; and the definition of an "applicable hospital." 89 Although a thirty-day post-discharge period was selected as the basis for examining readmission rates, CMS also mentioned its intent to "revisit the episode length in future rulemaking as we gain more experience." $" 90$ Moreover, CMS listed stroke and total hip and total knee arthroplasty (replacement) readmission data as possible future measures for the Inpatient Quality Reporting ("IQR") program. ${ }^{91}$ Although this does not necessarily indicate that these quality measures would become part of the Program, IQR data are reported on the HHS Hospital Compare website, which currently includes only the three initial measures used in the Program. ${ }^{92}$ Finally, CMS stated that it would consider, in future rulemaking, implementation of an appeals process for hospitals unsatisfied with their calculated expected readmissions ratios" as well as "the benefits of publicly reporting the patient mix characteristics and the pre- and postpatient-mix adjusted HCAHPS [(Hospital Consumer Assessment of Healthcare Providers and Systems)] scores of participating hospitals."94

\section{INTENDED CONSEQUENCES}

\section{"In the middle of difficulty lies opportunity." - Albert Einstein ${ }^{95}$}

While decreasing readmissions will not happen overnight, there are several positive indications that rates may be controllable. Interestingly, thirty-day rehospitalization rates during fiscal year 2004 ranged from 13.3\%

42 C.F.R. pts. $412,413,476)$.

89. Id. at 51,663 .

90. Id. at 51,619. See also infra Part X.

91. CMS Final Rule, 76 Fed. Reg. 51,476, 51,637 (Aug. 18, 2011) (to be codified at 42 C.F.R. pts. $412,413,476$ ). The IQR program was designed to provide health care consumers with more information regarding acute-care hospital performance in order to increase consumer choice while also giving hospitals a greater incentive to improve outcomes. Hospital participation in the IQR program is optional, but hospitals that do not participate receive an automatic two-percent deduction in their annual reimbursement rates. Hospital Inpatient Quality Reporting (IQR) Program Overview, QUALITYNET, http://qualitynet.org/ $\mathrm{dcs} /$ ContentServer?c=Page\&pagename $=$ QnetPublic\%2FPage\%2FQnetTier2\&cid=11381159 87129 (last visited Feb. 3, 2012).

92. Hospital Compare, U.S. DEP'T OF HEALTH \& HuMAN SERVS., http://www.hospital compare.hhs.gov/ (last updated Jan. 26, 2012).

93. CMS Final Rule, 76 Fed. Reg. 51,476, 51,673 (Aug. 18, 2011) (to be codified at 42 C.F.R. pts. $412,413,476$ ).

94. Id. at 51,660 . 2011).

95. Albert Einstein, The Ultimate Quotable Einstein 480 (Alice Calaprice ed., 
(in Idaho) to $23.2 \%$ (in the District of Columbia). ${ }^{96}$ The rehospitalization rate was wholly $45 \%$ higher in the five states that had the highest rates than in the five states that had the lowest rates. ${ }^{97}$ Generally, the Western states (with the exceptions of California and Arizona) had the lowest readmission rates while the Eastern and Midwestern states had the highest rates. ${ }^{98}$ While regional differences in physician mentality or patient compliance may account for some of these differences, it cannot adequately explain, for example, why Illinois had a $21.7 \%$ readmission rate while just to the north, Wisconsin had only $17.0 \%$; or why Kentucky had a $21.2 \%$ readmission rate while neighboring Indiana had only a $17.7 \%$ rate. ${ }^{99}$ While these differences may be baffling, they tend to point toward an important reality: readmission rates may be, more or less, within a provider's control. Perhaps, then, Texas $(19.4 \% \text { readmissions })^{100}$ could learn something from New Mexico (16.3\% readmissions), ${ }^{101}$ and hospitals nationwide could learn something from Idaho, with its nation-low $13.3 \%$ readmission rate. ${ }^{102}$

MedPAC and CMS have also indicated their conviction that readmissions are a controllable problem. ${ }^{103}$ In its June 2007 report to Congress, ${ }^{104}$ MedPAC offered several solutions to help ease the growing readmission problem. These are discussed in Part VIII, above. According to a March 2010 CBO report, the Hospital Readmissions Reduction Program should save $\$ 100$ million in fiscal year $2013 ; \$ 300$ million in $2014 ; \$ 1.1$ billion in 2015; $\$ 1.3$ billion in 2016 and 2017; $\$ 1.4$ billion in 2018; and $\$ 1.5$ billion in $2019 .{ }^{105}$ All told, this provision alone could thus save at least $\$ 7.1$ billion by $2019 .{ }^{106}$

Since the payment reduction factor is determined as a ratio of excess readmissions compared to overall discharges, it seems that hospitals whose numbers are lagging compared to their peers might remedy this predicament by choosing to see more total patients. This would increase the denominator and thereby lower excess readmissions as a portion of overall readmis-

96. Jencks et al., supra note 38, at 1424.

97. Id. at 1423.

98. Id. at 1424 .

99. Id.

100. Id.

101. Id.

102. Id.

103. See CMS Final Rule, 76 Fed. Reg. 51,476, 51,660 (Aug. 18, 2011) (to be codified at 42 C.F.R. pts. $412,413,476$ ) ("Many studies have demonstrated ... that hospitals and their partners have the ability to lower readmission rates.").

104. MEdiCARE PAYMENT AdVISORY COMM'N, supra note 31.

105. Letter from Douglas W. Elmendorf, Director, Cong. Budget Office, to Nancy Pelosi, Speaker, U.S. House of Representatives, providing a final cost estimate of the direct spending and revenue effects of the Patient Protection and Affordable Care Act, tbl. 5, at 4 (Mar. 20, 2010), available at http://www.cbo.gov/ftpdocs/113xx/doc11379/AmendRecon Prop.pdf.

106. Id. 
sions. ${ }^{107}$ Setting up the system to facilitate this type of competitive jockeying could actually have a net positive effect on health care overall, as it would mean a larger number of Medicare patients would be receiving treatment within a given month. However, for already overcrowded public hospitals, this may prove to be the proverbial straw that breaks the camel's back. $^{108}$

\section{UNINTENDED CONSEQUENCES}

Even with the price floor in place, the proposed cuts would have an extremely detrimental economic impact on hospitals. John Clark, M.D., J.D., Medical Director of Clinical Informatics at Indiana University ("IU") Health, said that member Methodist Hospital in Indianapolis, Indiana, had year-to-date admissions topping 80,000 by September of $2010 .^{109}$ Dr. Clark pointed out that for an extensive, high-volume health system like IU Health, even a one percent pay cut would mean "millions of dollars per year" in lost reimbursements. ${ }^{110}$ Faced with bankruptcy, hospitals that cannot compete in the readmissions game will simply choose to offer fewer services, or gravitate away from treating patients with the sanctioned diagnoses. "If you can't adapt, you have to cut back services," said Clark. ${ }^{111}$

This is not a threat unique to Indiana hospitals. Hospitals across the country are feeling the economic pinch even prior to implementation of the Affordable Care Act and the Hospital Readmissions Reduction Program. "Faced with mounting debt and looming costs from the new federal healthcare law, many local governments are leaving the hospital business, shedding public facilities that can be the caregiver of last resort." 112 Moody's Investors Service has predicted, "many standalone hospitals won't have the resources to invest in information technology or manage bundled payments well."113 What is more, "Many nonprofits have bad credit ratings and in a tight credit market cannot borrow money, either."114

107. For example, if a hospital had 50 readmissions for 100 patients, they might decide to expand services and accept 100 more patients in hopes that their readmissions ratio would decrease (i.e. from $50 / 100$ or $50 \%$ to $50 / 200$ or $25 \%$ ). CMS makes a similar acknowledgement in the Final Rule. CMS Final Rule, 76 Fed. Reg. 51,476, 51,675 (Aug. 18, 2011) (to be codified at 42 C.F.R. pts. 412, 413, 476). Cf. Arnold M. Epstein et al., The Relationship Between Hospital Admission Rates and Rehospitalizations, 365 NEW ENG. J. MED. 2287, 2294 (2011) (finding a "substantial association" between regional readmission rates and overall hospital admission rates).

108. See, e.g., Levine, supra note 23; see also infra Part VII.

109. Interview with John Clark, Medical Director of Clinical Informatics, Indiana University Health, in Indianapolis, Ind. (Sept. 17, 2010).

110. Id.

111. Id.

112. Suzanne Sataline, Cash-Poor Governments Ditching Public Hospitals, WaLl ST. J., Aug. 29, 2010 (Health Industry section).

113. Quoted in id.

114. Id. 
Although the individual health care mandate, ${ }^{115}$ which penalizes individuals who do not obtain health care coverage, may ease pressures on hospitals that treat higher numbers of uninsured patients, due to the Affordable Care Act's concomitant reduction in disproportionate share hospital ("DSH") payments, ${ }^{116}$ the effects of the mandate may be negligible on hospital bottom lines. Prior to the Affordable Care Act, DSH payments were structured such that hospitals which provided care to a large number of lowincome patients, such as those with Medicaid and the uninsured, could be at least partially compensated for their efforts. ${ }^{117}$ DSH payments are calculated based on a number of factors, but they are designed to compensate hospitals in proportion to the number of uninsured and indigent patients the particular hospital serves. ${ }^{118}$

Under the Affordable Care Act, however, HHS will reduce DSH payments to hospitals by seventy-five percent beginning in fiscal year 2015. ${ }^{119}$ Since readmissions tend to be higher in hospitals that treat more indigents, ${ }^{120}$ these hospitals will be hit doubly hard-losing reimbursements for readmissions while no longer getting the DSH payments to which they are accustomed. By misplacing provider incentives, this sort of reimbursement scheme will tend to have a disproportionate impact on the very hospitals providing the most benefit to society's most vulnerable members. Again, the impact of this reduction may be eased by the individual health care mandate, but the mandate itself allows for individuals to pay a fee to opt out of health care coverage, ${ }^{121}$ and violators may be difficult to track or bring to justice for a number of years because the IRS and HHS must work together to reconcile their records in order to catch freeloaders.

Related is the issue of what types of conditions the Hospital Readmissions Reduction Program includes in its payment reduction. With the increasing number of specialty hospitals, those that are not in the business of treating patients with one of the three specified conditions ${ }^{122}$ will get off nearly scot-free while specialty heart hospitals which treat a disproportion-

115. Patient Protection and Affordable Care Act, Pub. L. No. 111-148, $\S \S 1501,10106$, 124 Stat. 119, 242, 907 (2010).

116. Patient Protection and Affordable Care Act, Pub. L. No. 111-148, § 2551, 124 Stat. 119, 312-15 (2010) (codified as amended at 42 U.S.C. $\S 1396 \mathrm{r}-4(\mathrm{f})$ ) (reducing payments to Disproportionate Share Hospitals).

117. Christie Provost Peters, Nat'l Health Policy forum, The Basics: Medicaid Disproportionate Share Hospital (DSH) PAYMenTs 1 (2009), available at http://www.nhpf.org/library/the-basics/Basics_DSH_06-15-09.pdf.

118. Id. at 3 .

119. Patient Protection and Affordable Care Act, Pub. L. 111-148, § 3133(r)(1), 124 Stat. 119 (2010) (codified at 42 U.S.C. § 1395ww(d)(5)(F)(i) (2010)).

120. Richard Cooper, Hospital Readmission Policy Flawed, ACTION FOR BETTER HEALTHCARE (Aug. 13, 2010), http://actionforbetterhealthcare.com/?p=1067.

121. Patient Protection and Affordable Care Act, Pub. L. No. 111-148, §§ 1501, 10106, 124 Stat. 119, 242, 907 (2010).

122. The three conditions are heart attack, heart failure, and pneumonia. U.S. DEP'T OF HEALTH AND HUMAN SERVS., supra note 55. 
ately high number of patients with congestive heart failure or heart attack will stand to be unfairly penalized. Or worse, these specialty hospitals may opt not to treat Medicare patients at all, placing an ever-increasing burden of the sickest and oldest patients (who generally cannot afford private insurance) on Medicare hospitals. ${ }^{123}$

A Journal of Hospital Medicine study showed that when providers were more proactive with heart failure patient follow-up, including visit reminders, education, and regular feedback, ${ }^{124}$ they actually tended to see higher twelve-month readmission rates (49\% compared to $36 \%$ for the baseline group ${ }^{125}$ ), but lower mortality rates ( $24 \%$ compared to $30 \%$ for the baseline $\left.^{126}\right)$. A similar study published in the Archives of Internal Medicine compared readmission rates and mortality rates in patients who were part of a multidisciplinary, post-discharge heart failure management program and patients who received the usual follow-up care. ${ }^{127}$ Here, the participants in the special post-discharge program experienced "significantly decrease[d]" hospital readmissions, but no affect on mortality rates. ${ }^{128}$

These studies expose a potential inconsistency between the desired outcome of the Hospital Readmissions Reduction Program (better longterm health) and the likely result of the provision (immediate cost savings, but worse long-term health), indicating a misplaced incentive. It may be more appropriate to place the incentive on reducing mortality rates-which could be said to be the end goal of any medical care-rather than on readmissions, which may or may not indicate a failure of care quality. In one of the studies referenced above, the patients who were readmitted with less frequency actually died sooner than those who were readmitted more readily. ${ }^{129}$ This demonstrates what could be a significant problem with the HRRP.

VIII. PROPOSED SOlutions to READMiSSIONS-WHAT IS A PROVIDER TO Do?

There are several commonly attempted solutions to the readmission problem. Dr. John Clark stated ${ }^{130}$ that hospitals are trying a number of

123. Levine, supra note 23.

124. Alison Mudge et al., The Paradox of Readmission: Effect of a Quality Improvement Program in Hospitalized Patients With Heart Failure, 5 J. HosP. MED. 148, 149 (2010).

125. Id. at 151 .

126. Id.

127. Femida H. Gwadry-Sridhar et al., A Systematic Review and Meta-analysis of Studies Comparing Readmission Rates and Mortality Rates in Patients with Heart Failure, 164 ARCHIVES INTERNAL MED. 2315, 2315 (2004).

128. Id.

129. Mudge et al., supra note 124 , at 151.

130. Interview with John Clark, Medical Director of Clinical Informatics, Indiana University Health, in Indianapolis, Ind. (Sept. 17, 2010). 
methods, including telemonitoring, ${ }^{131}$ home health care, ${ }^{132}$ discharge follow-up, ${ }^{133}$ or simple medication reconciliation. ${ }^{134}$ However, Clark was hesitant to say that one method will work in all cases or that some combination of methods would not be more efficacious. So perhaps the statespecific readmissions data cited above ${ }^{135}$ might ultimately be less portable than it appears. The problem with any of the methods mentioned by Dr. Clark, however, is that they are all very expensive to implement and monitor. Beyond the huge initial cost of an electronic device for a patient, for example, lies the latent costs of monitoring, data gathering, and data storage for scores of targeted patients, all of which would be necessary for such a program to work properly and have any hope of achieving its desired result.

Certain studies have seemed to bolster some of the aforementioned methods. For example, one study of Philadelphia hospitals found that readmissions could be reduced by forty-five percent over a twenty-four-week period by having nurses meet repeatedly with high-risk patients. ${ }^{136}$ Other studies have shown the effectiveness of prompt telephone follow-up ${ }^{137}$ or hiring a "transition coach" to ease elderly patients' passage from hospital to home. ${ }^{138}$

One model that has proven successful is the Re-Engineered Discharge program, dubbed "Project RED."139 Developed at Boston University Medical Center, Project RED utilizes specially trained registered nurses called "discharge advocates" to help with eleven essential components of the discharge and handoff process:

(1) educating patients about their condition, (2) making appointments for clinician follow-up and postdischarge testing, (3) discussing tests and studies with patients, (4) organizing post-discharge services, (5) confirming medication plans, (6) reconciling discharge plans with national guidelines, (7) teaching patients to identify and deal with emergency medical situations, (8) expediting the transmission of the dis-

131. This entails equipping the patient with a PDA or other electronic device that automatically sends health data back to the physician.

132. This typically involves a nurse or other practitioner who administers care at the patient's home.

133. A process which would include making telephone contact with the patient, especially within the crucial first few days after a discharge.

134. In other words, making sure the patient's medicines are not hindering each other's efficacy or causing other side effects due to interaction.

135. Jencks et al., supra note 38, at 1424.

136. MEDICARE PAYMENT ADVISORY COMM'N, supra note 31.

137. Id.

138. Id.

139. U.S. Cong. ReSEARCH SERV., R40972, MEdiCARE Hospital Readmissions: ISSUES AND POLICY OPTIONS 18 (2009). 
charge summaries to outpatient physicians, (9) asking patients to explain their care plans to assess patient's degree of understanding, (10) giving patients written discharge plans at the time of discharge, and (11) providing telephone support shortly after discharge to reinforce the patient's discharge plan. ${ }^{140}$

In one study involving Project RED, the 370 patients enrolled in the program were one-third less likely to be readmitted to the hospital than the control group, who did not participate in the program. More than ninety percent of program participants received some form of follow-up within twenty-four hours of leaving the hospital. ${ }^{141}$

The fact that more than half of rehospitalized patients have not seen a physician between discharge and readmission ${ }^{142}$ seems easily remedied, but the costs of doing so for the hundreds of thousands of patients a large hospital might see per year would be staggering. The economic harm is especially great given that there is no reward under the Hospital Readmissions Reduction Program for reducing readmissions, only a penalty for not doing so. ${ }^{143}$

Another promising solution, currently underway at selected Kaiser Permanente hospitals in California, is the use of handheld video cameras to monitor chronically ill patients readmitted within thirty days. ${ }^{144}$ Kaiser's so-called "video ethnography" program involves arming caregivers and social scientists with video cameras in order to record interviews with patients. ${ }^{145}$ The team accompanies patients home to see how medications are being managed and to interview aides and family members in order to establish a sense of how well the patient is managing his or her medication regimen. ${ }^{146}$ They also interview pharmacists, home health providers, nurses, and other physicians in an effort to get an accurate (and intimate) overall picture of how the patient is managing his or her condition. ${ }^{147}$ These videos

140. Id.

141. Id.

142. Peter R. Orszag \& Ezekiel J. Emanuel, Health Care Reform and Cost Control, 363 NEW ENG. J. MED. 601, 602 (2010).

143. This predicament is discussed in more depth in Janice Simmons, Reducing Readmissions: Are Quality Payments a Carrot or Stick? HEALTHLEADERS MEDIA (Jan. 28, 2010), http://www.healthleadersmedia.com/page-1/QUA-245642/Reducing-Readmissions-Are-

Quality-Payments-a-Carrot-or-Stick ("With the rates of readmissions initially higher for poorer population groups, hospitals treating them will be penalized even when they try to bring these readmissions down from a high level." (quoting Richard Cooper, M.D.)).

144. See Cheryl Clark, Readmissions Reduction Effort at Kaiser Involves Cameras, HEALTHLEADERS MEDIA (Dec. 16, 2010), http://www.healthleadersmedia.com/content/QUA260274/Readmissions-Reduction-Effort-at-Kaiser-Involves-Cameras.

145. See id.

146. See id.

147. See id. 
are then shared and reviewed by providers at the hospital, who may then spot areas for improvement. ${ }^{148}$ Kaiser found the process extremely helpful in combatting a common problem with patient self-reporting: "[W]hat people say they do and what they actually do are sometimes different," said Kaiser's director of field studies, Estee Neuwirth. ${ }^{149}$ In a recent six-month period, Kaiser Permanente's South Bay Medical Center in Harbor City, near Los Angeles, was able to reduce readmissions from $15.7 \%$ to $9 \%$. ${ }^{150}$

A final example of a successful readmission reduction effort is the integrated community approach to health care taken by the community of Grand Junction, Colorado. ${ }^{151}$ The community includes a mixture of Medicare- and Medicaid-eligible individuals, but the dominant payer in the region is a non-profit health maintenance organization ("HMO"), Rocky Mountain Health Plans. ${ }^{152}$ The success of this model is largely attributed to the HMO's great influence over all providers in its network. ${ }^{153}$ Examples of Rocky Mountain Health Plans' influence include "requiring providers to serve all lines of business; paying for medical review across settings to improve care coordination; reinvesting profits in community priorities, such as an electronic information exchange; and providing mobile and Web-based clinical support tools and generic drug samples to individual providers." This was complemented by "mature" health care services and practices such as "information exchange, equitable payment arrangements, shared support of the clinic for the poor, and expectations of regular exchanges of site visits among members of the medical community."155 This integrated system allowed the community's dominant provider, St. Mary's Hospital, to achieve significantly lower rehospitalization rates and post-hospitalization mortality rates as compared with twenty comparison hospitals. ${ }^{156}$ The major drawback with a managed care approach like Grand Junction's is that it seems better suited for smaller communities with only one or two major providers, but may be substantially more difficult to implement in a larger city with a more complicated provider network.

In short, while some hospitals and health systems have found ways of reducing readmissions - at least in the near term - the above case studies also reveal an important reality confronting hospitals as they seek to navigate the Hospital Readmissions Reduction Program: there are as just as

148. Id.

149. Quoted in id.

150. Clark, supra note 144.

151. Marsha Thorson et al., Grand Junction, Colorado: How a Community Drew on its Values to Shape a Superior Health System, 29 HEALTH AFF. 1678 (2010).

152. Id.

153. Id.

154. Id. at 1684 .

155. Id.

156. Id. 
many solutions to higher readmissions as there are apparent causes. ${ }^{157}$ Even if certain populations have predictably higher readmissions than others, ${ }^{158}$ a practical, universal solution for providers has yet to be proposed. This is where Congress should step in and revise the statute, or CMS should alter its interpretation of the HRRP.

\section{POLICY IMPLICATIONS OF READMISSIONS REDUCTION}

While readmissions are decidedly undesirable, as demonstrated above, decreasing readmissions may be an elusive problem to fix. Former Director of the White House Office of Management and Budget, Peter Orszag, $\mathrm{Ph}$.D., who played a prominent role in the health care overhaul that culminated in passage of the Affordable Care Act, cited a study in the Journal of the American Medical Association ("JAMA") ${ }^{159}$ to assert that early followup is the key to reducing readmissions. ${ }^{160}$ But Richard Cooper, MD, Professor of Medicine and Senior Fellow at the Leonard Davis Institute of Health Economics at the University of Pennsylvania, begged to differ. ${ }^{161}$ Having read the same JAMA report, Cooper surmised that the data shows, even as early physician follow-up visits increased, the percent of readmissions stayed constant. ${ }^{162}$ In other words, according to Cooper, there is no correlation between early follow-up and a reduction in hospital readmission rates.

But perhaps Orszag and Cooper are both putting the cart before the horse. A study by medical researchers at the Cleveland Clinic suggests that readmissions may not even be an accurate measure of long-term patient outcomes. ${ }^{163}$ Although the conventional wisdom is that a patient being re-

157. It seems Congress may have been aware of the nebulous nature of the problem, as the Hospital Readmissions Reduction Program includes a provision exempting "sole community hospitals" and "Medicare-dependent, small rural hospitals" from its payment penalties. Apparently, even Congress was afraid some hospitals would not be able to lower readmissions rates on their own. See 42 U.S.C. $\S 1395 w w(q)(2)(B)(i)(2010)$.

158. See, e.g., Mudge et al., supra note 124, at 61-67 (finding that chronic disease, depressive symptoms, and being underweight put patients at higher risk for readmission); Roxana Guilford-Blake, Medicaid Status, Race Linked with Hospital Readmissions, HEALTHLEADERS MEDIA, Oct. 15, 2010, http://www.healthleadersmedia.com/content/LED257766/Medicaid-Status-Race-Linked-with-Hospital-Readmissions (finding that, after adjustments for other variables, being African-American raises risk of readmission by fortythree percent and being a Medicaid beneficiary raises risk of readmission by fifteen percent).

159. Adrian F. Hernandez et al., Relationship Between Early Physician Follow-up and 30-Day Readmission Among Medicare Beneficiaries Hospitalized for Heart Failure, 303 JAMA 1716, 1716-22 (2010).

160. Peter R. Orszag \& Ezekiel J. Emanuel, Health Care Reform and Cost Control, 363 NEW ENG. J. MED. 601, 602 (2010).

161. Richard Cooper, Hospital Readmission Policy Flawed, ACTION FOR BETTER HEALTHCARE (Aug. 13, 2010), http://actionforbetterhealthcare.com/?p=1067.

162. Id.

163. Karen Pallarito, High Readmission Rates May Not Mean Worse Hospital Care, U.S. NEWS \& WORLD REP. (July 14, 2010), http://health.usnews.com/health-news/family- 
admitted to the hospital within thirty days of an initial stay is a wasteful use of resources and a sign of poor-quality care generally, the study observed that, at least in the case of heart failure patients, being readmitted to the hospital after an inpatient stay may actually preserve a patient's life. ${ }^{164}$ In an analysis of newly available government data for 3857 hospitals, the researchers discovered that higher readmission rates following an initial hospitalization for heart failure actually correlated with a lower risk-adjusted, thirty-day death rate. ${ }^{165}$ In 2000 , a survey of some nineteen readmission studies carried out over the previous ten years concluded starkly, "[M]ost readmissions seem to be caused by unmodifiable causes, and ... pending an agreed-on method to adjust for confounders, global readmission rates are not a useful indicator of quality of care."166 Perhaps, then, penalizing readmissions is not the soundest way of reducing Medicare costs after all. Rather, "[t]his needs to be investigated further and we need to improve it" $"$ in order to avoid unnecessarily decreasing care quality in the name of costcutting. ${ }^{168}$

Although the Hospital Readmissions Reduction Program is a start, it is far from perfect. The major problem with the program is that it attempts to do too much in one fell swoop. The program simultaneously gathers uniform data among hospitals, publicizes those results, and metes out monetary penalties. This may lead to an overextension of HHS resources, especially given the relatively short timeframe in which providers must comply.

While gathering more data on the issue is undoubtedly a key to appropriately and intelligently tackling the problem of excess readmissions, the fact that hospital readmission data will become public serves to doubly penalize hospitals that take a bit longer to find a workable remedial mechanism. Since there are so many plausible solutions but no one-size-fits-all choice, Congress or CMS should consider implementing the two phases of the program at different times: first, implementing the standards and conducting data-gathering, and second, penalizing for persistently high readmission rates.

health/heart/articles/2010/07/14/high-readmission-rates-may-not-mean-worse-hospitalcare.html.

164. Id.

165. Id.

166. Jochanan Benbassat \& Mark Taragin, Hospital Readmissions as a Measure of Quality of Health Care: Advantages and Limitations, 160 ARCHIVES INTERNAL MED. 1074, 1074 (2000).

167. Pallarito, supra note 163 (quoting Denise Love, Executive Director of the National Association of Health Data Organizations).

168. Another New England Journal of Medicine study concluded that, with the uncertain exception of heart failure patients, early follow-up and coordination of support with home caregivers did nothing or were unreliable in reducing readmissions. The study concluded, "Better discharge practices are necessary but not sufficient." Amy E. Boutwell et al., Discharge Planning and Rates of Readmissions, 362 NEW ENG. J. MED. 1244, 1244 (2010), available at $\mathrm{http} / / / \mathrm{www} . n$ ejm.org/doi/pdf/10.1056/NEJMc1001131. 
Admittedly, this approach may not save as much money as originally devised. However, one major point of suspicion in the government's logic is the CBO budget estimates on which the program relies. The CBO's budget estimates continue to increase at a near-perfect linear rate even for the four years after the floor adjustment factor has reached its peak in 2015. ${ }^{169}$ Perhaps the rates are predicted to level off soon thereafter (the CBO estimate runs only through 2019), but it is highly dubious that the amount of money saved from the program would continue to increase even after the highest reduction in reimbursements has leveled out and hospitals have presumably adapted to the new measures the Affordable Care Act has put in place.

Another major weakness of the HRRP is a lack of clear goals, as demonstrated by incorrect or vague definitions of important terminology. As one example, CMS has neglected to exclude unrelated readmissions in its assessment of penalties to hospitals. When confronted with concerns over the fairness of this practice and asked to exclude readmissions related to random events, CMS responded, "In our view, readmissions that are truly unrelated to the hospitalization should not affect some hospitals more than others, because these readmissions should have the same probability of occurring for similarly situated patients, regardless of where the patient was initially hospitalized." ${ }^{\prime 70}$ Conceding that the measure is inadequate but yet will produce no prejudice due to uniform application amounts to a shirking of CMS' important responsibilities. Consistently employing a misguided standard does not magically transform it into a sensible one.

The fact is CMS was presented with a logical and viable second option in crafting its standard for potentially preventable readmissions. In 2008 , several doctors and medical researchers with $3 \mathrm{M}$ Health Information Systems created a method for determining whether a readmission is "potentially preventable." system employs a mathematical formula "based on the relationship between the reason for the original admission and the reason for the readmission."173 Doctors and researchers developed over 98,000 admission-readmission diagnosis pairs for the computerized system and categorized them according

169. See letter from Douglas W. Elmendorf, Director, Cong. Budget Office, to Nancy Pelosi, Speaker, U.S. House of Representatives, providing a final cost estimate of the direct spending and revenue effects of the Patient Protection and Affordable Care Act 26 (Mar. 20, 2010), available at http://www.cbo.gov/ftpdocs/113xx/doc11379/AmendReconProp.pdf. It should be noted that this data is calculated only through fiscal year 2019.

170. CMS Final Rule, 76 Fed. Reg. 51,476, 51,668 (Aug. 18, 2011) (to be codified at 42 C.F.R. pts. $412,413,476$ ).

171. See generally Norbert I. Goldfield et al., Identifying Potentially Preventable Readmissions, 30 HEALTH CARE FIN. REv. 75, 75-91 (2008).

172. Id. at 76 .

173. Id. 
to whether or not they were clinically related and therefore preventable. ${ }^{174}$ Clinical diagnoses from over five million hospital admissions in Florida between 2004 and 2005 were used as raw data, which, after accounting for cases that could not be used (for example, cases in which the patient died), left over three million admissions as valid data points. ${ }^{175}$ The results of the study show how few readmissions are truly related to their initial diagnoses. For example, even the two medical and surgical diagnoses with the largest percentage of potentially preventable readmissions barely reached the twenty percent threshold for rate of readmissions being potentially preventable. ${ }^{176}$ Thus, according to this detailed study, at least eighty percent of readmissions are completely unrelated to their initial diagnoses.

The 3M method recognizes the reality that any "analysis of hospital readmissions is complicated by the fact that not all readmissions are preventable, even with optimal care." fact and simply resigns itself to reasoning that if a measurement applies equally across all parties involved, it must be fair. The $3 \mathrm{M}$ study shows that, under CMS' structuring of the HRRP, hospital readmission results will be attributable solely to fortune (or lack thereof) about eighty percent of the time. This is unacceptable in a system designed to pay for performance. CMS's reason for rejecting the $3 \mathrm{M}$ study was that it "did not accurately specify what is related or unrelated simply by looking at the diagnoses for the admission and the readmission"178 and that the idea of excluding unrelated readmissions "could be subjective and prohibitively complex." "Instead, CMS adopted an approach that examines readmissions, the sample size for each qualifying hospital, and "[p]atient-risk factors, including age, and chronic medical conditions"180 to calculate a "risk-standardized readmission ratio for each hospital." 181 This risk-standardized readmission ratio is "then multiplied by the national crude rate of readmission for the given condition to produce a risk-standardized readmission rate."182 Somehow, CMS reasons that this system will be less subjective and complex than the carefully crafted $3 \mathrm{M}$ computer program. Moreover, the $3 \mathrm{M}$ study made clear distinctions between related, preventable readmissions and unrelated, unpreventable readmissions; whereas, as applied in the statute and regulations, the term "potentially preventable" is never even examined or truly defined in a way that makes it a functional benchmark for hospitals to use

174. Id. at 78 .

175. Id. at 79 .

176. Id. at 84 .

177. Id. at 75 .

178. CMS Final Rule, 76 Fed. Reg. $51,476,51,669$ (Aug. 18, 2011) (to be codified at 42 C.F.R. pts. $412,413,476$ ).

179. Id. at 51,621 .

180. Id.

181. Id.

182. Id. 
in improving readmission numbers.

One final weakness of the HRRP is that it provides that other "applicable conditions" 183 may be chosen by the Secretary of HHS. This would happen through regulations rather than via statute, circumventing Congress' deliberative processes and the certainty that is provided through clear rules set out in advance.

\section{Proposed Solutions}

While the problems with the Hospital Readmissions Reduction Program are various, the solutions may be equally so. Although each hospital is, at present, left to fend for itself against the imminent threat of possible payment reductions due to excess readmissions, struggling hospitals would do well to take note of some of the successful models in place at other hospitals explained above. Since there appears to be no panacea, perhaps it is best that neither Congress nor HHS has yet mandated a specific readmission reduction regimen as part of its Hospital Readmissions Reduction Program. Allowing hospitals to self-determine their game plans at least retains a measure of competition between providers that allows the savvy to survive and prosper. Even among the two-thirds of urban U.S. hospitals operating as nonprofits, ${ }^{184}$ most of which are tax-exempt and must therefore reinvest net income and abide by certain other governmental restrictions, ${ }^{185}$ there is a great degree of latitude in terms of operational decisionmaking. ${ }^{186}$ Still, there are certain actions Congress should take to amend the Affordable Care Act, which will allow it to be more effective in easing readmissions and more realistic in incentivizing hospitals to help out in the effort.

Perhaps Congress' principal oversight in drafting the Hospital Readmissions Reduction Program is that readmissions are not the best measure of hospital quality. ${ }^{187}$ Even so, reducing readmissions is a worthy endeavor, as it leads to cost savings and greater satisfaction among patients, payers, and providers. ${ }^{188}$ Another major policy problem with the program is that it attempts to do too much all at once. By simultaneously gathering uniform

183. 42 U.S.C. $\S 1395 w w(q)(5)(B)(2010)$.

184. The remaining third is split between for-profit and government ownership. Jill R. Horwitz, Making Profits and Providing Care: Comparing Nonprofit, For-Profit, and Government Hospitals, 24 HEALTH AFF. 790, 790 (2005), available at http://content. healthaffairs.org/content/24/3/790.full.pdf.

185. See 26 U.S.C. $\S 501$ (c)(3) (2011) ("[N]o part of the net earnings [may] inure[] to the benefit of any private shareholder or individual ....").

186. Telephone interview with John Clark, Medical Director of Clinical Informatics, Indiana University Health (Feb. 2, 2011); see also 26 U.S.C. $\S 501$ (c)(3) (2011) ("[N]o part of the net earnings [may] inure[] to the benefit of any private shareholder or individual . . . .").

187. See supra Part IX.

188. See JENNY MinotT, REducing Hospital READMISSIONS 9 (2008), available at http://www.academyhealth.org/files/publications/Reducing_Hospital_Readmissions.pdf. 
data among hospitals, publicizing those results, and meting out monetary penalties, the program may handicap hospitals before they have a chance to react to the novelty of the scheme. Furthermore, the wide-ranging implementation of the Affordable Care Act will be nearly in full swing by fiscal year 2013, ${ }^{189}$ and it will undoubtedly have hospitals reeling from regulatory overload. Thus, the first major change to the legislation should be to lengthen the timetable in implementing the Hospital Readmissions Reduction Program. Delaying commencement of the program until 2014 or later would give Congress time to revise and improve the program while allowing hospitals a sufficient period to research and address their individual plans of action before putting their federal reimbursement dollars on the line.

Second, the terms "potentially preventable" and "excess" readmissions need to be better defined in order to make them useful benchmarks for hospitals to use in improving their readmissions numbers. By the time the final rule regarding the HRRP was published in August 2011, hospitals were given barely more than a year to create and implement a successful program reducing readmissions before potentially losing millions of dollars a year in reimbursement payment reductions. Section 3011 of the Affordable Care Act required the Secretary of HHS to develop and submit to Congress, no later than January 1, 2011, a national strategy to improve the delivery of health care services, patient health outcomes and population health. ${ }^{190}$ On March 21, 2011, the Secretary submitted such a report. ${ }^{191}$ However, readmissions were mentioned only twice in the twenty-seven page report, and the only tangible measures of readmissions were the thirtyday all-cause readmission rate and the "[p]ercentage of providers who provide a summary record of care for transitions and referrals." 192 The clock is ticking for hospitals, but they have yet to receive any meaningful guidance from the government on how they will be adjudicated in their quest to reduce readmissions.

Third, Congress or CMS should tweak the criteria on which hospitals will be evaluated to be more objective and less capricious. The program should take into account the processes and safeguards hospitals have implemented rather than looking purely at final readmissions figures and assessing penalties based on outcomes that may or may not be within the hospital's control. Dr. John Clark of IU Health said that, in his estimation,

189. See generally Patient Protection and Affordable Care Act, Pub. L. No. 111-148, 124 Stat. 119 (2010).

190. Patient Protection and Affordable Care Act, Pub. L. No. 111-148, § 3011, 124 Stat. 119, 378 (2010) (codified as amended at 42 U.S.C. $\$ 241$ et seq.).

191. See U.S. Dep't of Health and Human Servs., National Strategy for QUALITY IMPROVEMENT IN HEALTH CARE (2011), available at $\mathrm{http}: / / \mathrm{www}$. healthcare.gov/law/resources/reports/nationalqualitystrategy032011.pdf.

192. Id. at 24. 
hospitals would prefer to be judged on quality of discharge and quality of handoff. ${ }^{193}$ "Are we doing everything we can?" is the important question. "If so, then there may be an intervening cause that's out of our hands." 194 Clark's point is that hospitals may be trying everything they can to ensure a patient receives quality care and appropriate and timely follow-up, but sometimes there are factors entirely outside of the provider's control that cause a patient to be readmitted unexpectedly. Accidents happen, and forgetful or obstinate patients do not always follow physician instructions to the letter, or at all. Objectifying and standardizing the benchmarks for progress ${ }^{195}$ will give hospitals concrete goals instead of leaving them fishing in the dark for a solution to lower readmissions. At the very least, adoption of a more realistic readmission measure-such as 3M's approach of penalizing only readmissions that were somehow related to the initial discharge ${ }^{196}$ would be of assistance to hospitals struggling to comply. This change should be a priority for CMS if the Hospital Readmissions Reduction Program is to effectuate its desired outcome within its desired timeframe.

Fourth, the Hospital Readmissions Reduction Program should not do away with DSH payments at this time. DSH payments are a major boon for increasing and preserving minority and impoverished access to care, as they compensate hospitals that treat indigent populations. ${ }^{197}$ Therefore, eliminating DSH payments creates incentive for hospitals to alter their array of services to those more profitable and less commonly utilized by needy patients. As hospitals seek to diversify and economize, less profitable services, such as prevention and screening, ${ }^{198}$ will be curtailed. ${ }^{199}$ The reason for such cutbacks is that hospitals need to be able to anticipate their cash flows in advance. ${ }^{200}$ Even though screening might increase a patient's health and reduce his or her lifetime medical expenses, network hospitals do business on a yearly basis; consequently, anything that can be pushed back until the following year would tend to be overlooked. This again creates a skewed incentive. Instead, the Affordable Care Act should encourage proactive screenings and prophylactic treatments. This would likely do far more to stem rising health care costs, as patients' medical problems could be detected and treated before they ballooned into much more serious - and

193. Telephone interview with John Clark, Medical Director of Clinical Informatics, Indiana University Health (Feb. 2, 2011).

194. Id.

195. This could be done by simply giving a list of best practices and requiring that hospitals follow most or all of them in order to receive full Medicare funding.

196. See Goldfield et al., supra note 171 , at 75 .

197. See PETERS, supra note 117 , at 3 .

198. This would include social work services, colonoscopies, and mammograms, among many others. Telephone interview with John Clark, Medical Director of Clinical Informatics, Indiana University Health (Feb. 2, 2011).

199. Id.

200. Id. 
more expensive-maladies. ${ }^{201}$

\section{CONCLUSION}

In summary, while the Hospital Readmissions Reduction Program is aimed at an important and costly problem, Congress may have utilized too much "stick" and not enough "carrot" to induce hospitals to adequately comply with the provision. The overbroad language and underwhelming specificity of the statute not only keep hospitals guessing as to how to best comply with its terms, the program also stands to create real problems in public health care in America: namely, a decrease in health care quality, a decrease in minority access to care, and an increase in hospital financial difficulties. With clarification of certain terms and redirection of a few incentives, the Hospital Readmissions Reduction Program could make a positive and notable impact on the United States' budget ${ }^{202}$ and on public health care quality in general.

201. But see Pub. L. No. 111-148, $§ 2713,124$ Stat. 119 (2010) (codified at 42 U.S.C. $\S 300 \mathrm{gg}-13(2010)$ ) (providing that private insurers are mandated to cover screening services and preventive treatments which have been given a recommendation of " $A$ " or " $B$ " by the U.S. Preventive Services Task Force); USPSTF $A$ and $B$ Recommendations, U.S. PREVENTIVE SERVS. TASK FORCE, http://www.uspreventiveservicestaskforce.org/uspstf/ uspsabrecs.htm (last updated August 2010). It should be noted, however, that although insurers must cover such procedures, hospitals are not required or incentivized to administer them; therefore, macro-level improvements may still be slow or remain unrealized.

202. Letter from Douglas W. Elmendorf, Director, Cong. Budget Office, to Nancy Pelosi, Speaker, U.S. House of Representatives, providing a final cost estimate of the direct spending and revenue effects of the Patient Protection and Affordable Care Act 26 (Mar. 20, 2010), available at http://www.cbo.gov/ftpdocs/113xx/doc11379/AmendReconProp.pdf. 